\title{
Behavioral Models of Pain States Evoked by Physical Injury to the Peripheral Nerve
}

\author{
Linda S. Sorkin and Tony L. Yaksh \\ Department of Anesthesiology, University of California, San Diego, California 92093-0818
}

\begin{abstract}
Summary: Physical injury or compression of the root, dorsal root ganglion, or peripheral sensory axon leads to welldefined changes in biology and function. Behaviorally, humans report ongoing painful dysesthesias and aberrations in function, such that an otherwise innocuous stimulus will yield a pain report. These behavioral reports are believed to reflect the underlying changes in nerve function after injury, wherein increased spontaneous activity arises from the neuroma and dorsal root ganglion and spinal changes increase the response of spinal projection neurons. These pain states are distinct from those associated with tissue injury and pose
\end{abstract}

particular problems in management. To provide for developing an understanding of the underlying mechanisms of these pain states and to promote development of therapeutic agents, preclinical models involving section, compression, and constriction of the peripheral nerve or compression of the dorsal root ganglion have been developed. These models give rise to behaviors, which parallel those observed in the human after nerve injury. The present review considers these models and their application. Key Words: Tactile allodynia, spontaneous pain, dorsal root ganglion, nerve compression, autotomy.

\section{INTRODUCTION}

Classic observations in humans emphasize that nerve section can lead to sensory experiences that reflect the neural organization that originally subserved the body region innervated by the sectioned nerve. Frequently this "phantom" is reported as painful. ${ }^{1}$ Incomplete injury to a nerve trunk, as generated by blunt trauma or chronic compression, will lead to well characterized ongoing sensations (dysesthesias) and exaggerated sensitivity to otherwise innocuous stimuli (e.g., allodynia). ${ }^{2}$ Current thinking suggests that mechanical allodynia represents activity in low threshold afferents. ${ }^{3}$ The functional mechanisms underlying these pain states are presumed to result from post-injury changes. At a systems level, nerve injury results in increases in ectopic activity from the nerve at the site of injury (e.g., the neuroma) and/or at the dorsal root ganglion (DRG) of the injured axons. ${ }^{4}$ Injury produces alterations in dorsal horn excitability, leading to lowered thresholds in dorsal horn neurons and increases in their receptive field size. ${ }^{5}$ Several mechanisms have been identified that are believed to underlie these changes.

Address correspondence and reprint requests to: Linda S. Sorkin, Ph.D., Department of Anesthesiology, University of California, San Diego, 9500 Gilman Dr., Mail Code 0818, La Jolla, CA 92093-0818. E-mail: 1sorkin@ucsd.edu; or Tony L. Yaksh, Ph.D., Department of Anesthesiology, University of California, San Diego, 9500 Gilman Dr., La Jolla, Mail Code 0818, CA 92093-0818. E-mail: tyaksh@ucsd.edu.
Three points should be made: 1) Although understanding the biology of nerve injury can be approached through morphological and biochemical assessments, the role played by those mechanisms in the nociceptor, produced by nerve injury, requires a behavioral correlate reflecting the "pain" state of the organism; 2) when a mechanism is proposed that is believed to underlie neuropathic pain, drugs targeting that mechanism must have corollary effects on the behavior of the animal; and 3) meaningful validation of the preclinical model depends on demonstration of a parallel pharmacology (when possible) with that observed in the human condition. A variety of drug classes have indeed been shown to have efficacy. These include certain anticonvulsants (such as gabapentin), ${ }^{6}$ sodium channel blockers (such as lidocaine), ${ }^{7}$ and various amine uptake inhibitors, notably those which block norepinephrine and serotonin transporters (such as amitriptilline). ${ }^{8}$ Opiates are also used and have reported efficacy. ${ }^{9,10}$ In the past several years, many other targets/agents have been implicated, but assertions of their efficacy must be considered, dependent on the still evolving data sets.

The importance of behavioral paradigms in devising targets and specific drugs to act on them in neuropathic pain regulation has led to an increased implementation of behavioral models. In general, the types of nerve injury models can be broadly divided into those that produce a complete or partial physical injury to a component of the 

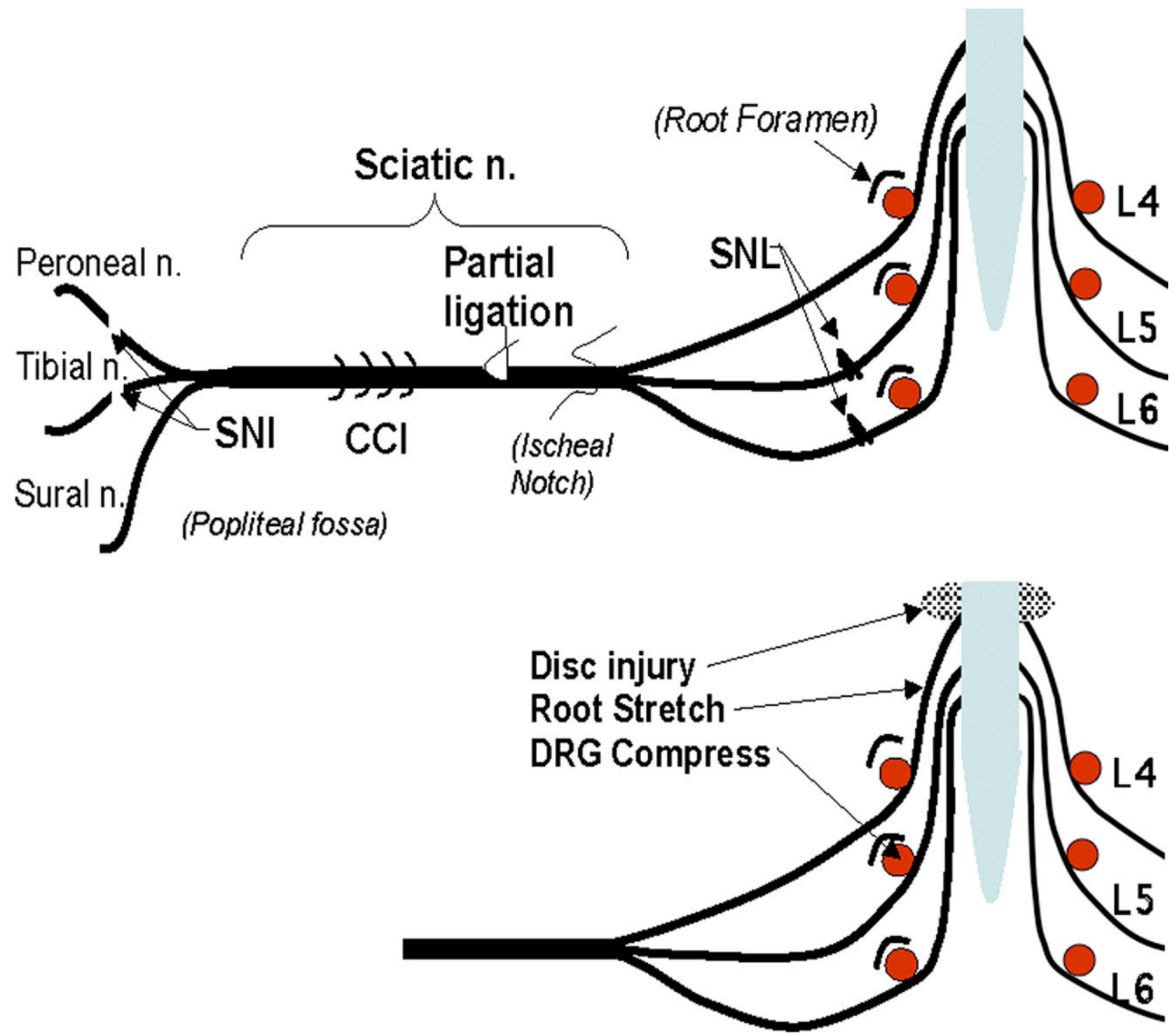

FIG. 1. Schematic summary of several surgical injuries to the peripheral nerve (above) and injuries to the dorsal root ganglion (DRG) and dorsal root (below), which resulted in pathological pain states. $\mathrm{CCl}=$ chronic constriction injury; Peroneal $\mathrm{n}$. = peroneal nerves; Sciatic $\mathrm{n}$. = sciatic nerve; SNI = spared nerve injury; Sural $\mathrm{n}$. = sural nerve; $\mathrm{SNL}=$ sciatic nerve ligation; Tibial $\mathrm{n} .=$ tibial nerve.

peripheral sensory nerve DRG or root. The injury may be induced by mechanical (i.e., section, crush, or compression), chemical, metabolic, or immunological insult directed at some or all of the aforementioned anatomic elements. Because of the breadth of the material, we have limited our focus to those injuries that are generally considered to be peripheral to the spinal cord. It should also be noted that the aim of the present commentary is to consider those reports that seek to establish the treatment as a model. Thus, many interventions have been reported, but at the least, for such a treatment to be considered a model, there should be effort to characterize time course, and, where relevant, elements that impact the expression of the behavioral phenotype. Unfortunately, this is not always appreciated. The impact of a variety of animal (genetic, gender), environmental (stressors, housing, diurnal cyclicity, or presence of investigator), and treatment (diet) variables on the expression of a neuropathic pain phenotype have been extensively reviewed elsewhere. ${ }^{11-13}$ In the following sections, we review representative injuries specifically generated by physical trauma to the peripheral nerve. A summary of these interventions is presented in FIG. 1.

\section{NERVE SECTION}

In the course of studying regenerating nerves, it was observed that complete lesion of the sciatic nerve during a period of days to weeks would lead to self-injury to the digits and distal extremities, formerly innervated by the 
sectioned nerve. Such autotomy has been observed after complete sciatic section, ${ }^{14}$ crush, ${ }^{15}$ or cryolesions (transient freezing). ${ }^{16}$ Trunk lesions have been observed to produce such autotomy in several species. This model was proposed by Wall et al. ${ }^{14}$ to be a model of anesthesia dolorosa in man. Complete trunk lesions have been reported to yield other aberrant behaviors targeted at the denervated limb in several species, including the mouse, rat, rabbit, and primate ${ }^{17}$ Importantly, lesions limited to nerve trunk branches, such as the saphenous ${ }^{18}$ or the tibial/common peroneal ${ }^{19,20}$ fail to produce autotomy. The principle concern from the outset has been the controversy as to whether this self-mutilation is an index of a painful experience or an abnormal sensation (or even a lack of sensation). Although controversial, considerable evidence supports the conclusion that deafferentation yields behaviors that are an index of the degree of dysesthesia that results from limb deafferentation, as reported in humans. ${ }^{21,22}$

Several variables have been shown to influence autotomy after nerve section, including gender (incidence of autotomy is greater in males than in females), ${ }^{23}$ strain $^{24}$ (autotomy is a single-gene recessive trait ${ }^{25}$ ), and method of section. Systematic comparison revealed that the lowest incidence of autotomy after sciatic neurectomy was noted after injury with a $\mathrm{CO}_{2}$ laser, tight ligation, or severance with scissors; comparatively, cryoneurolysis and electrocautery yielded higher autotomy scores. ${ }^{26}$

\section{NERVE LIGATIONS}

Currently, the most intensely investigated of the traumatic animal neuropathic pain models are those involving a surgical trauma/ligation of the sciatic, spinal, or peripheral nerves. Axotomy and nerve crush were first used to investigate effects of denervation and neuroma development, but have been gradually superceded by injuries, which only partially denervate the tissue and involve the sympathetic nervous system to some extent. The following sections will discuss the ligation models. An interesting article to be considered is one by Dowdall et $\mathrm{al}^{27}$ who undertake a concurrent assessment in the same laboratory of several of the models discussed below using a variety of end points.

\section{Chronic loose ligation}

The Bennett or chronic constriction injury (CCI) model was the first of these models. ${ }^{28}$ Surgical preparation involves placement of loose ligatures located $1 \mathrm{~mm}$ apart on the mid-sciatic nerve. Ligatures are tied such that flow through superficial epineural vasculature is reduced, but not eliminated. This procedure results in sciatic nerve swelling, a substantial loss of axons distal to the ligatures and neuroma formation at the level of the ligatures. Nerve swelling and pain behavior are enhanced if the ligatures are chromic gut, as they contribute to the immune component of the neuropathy. ${ }^{29}$ There is a major loss of myelinated fibers followed by unmyelinated fibers. ${ }^{30-32}$ Loss of myelinated fibers is usually reported to outnumber that of unmyelinated fibers, although both inspection of histology and examination of conduction velocity may have confused demyelinated A fibers with $\mathrm{C}$ fibers and thus, inflated their number. Growth cones are present at the level of the ligatures and signs of remyelination and fiber regeneration distal to the ligatures have been reported. In all cases, macrophage infiltration $^{33}$ is believed to play a major role in the etiology of the nociception. Variations of the procedure are performed on branches of the trigeminal nerve. ${ }^{34-36}$ Pain behavior and electrophysiological changes resulting from CCI have been reported in rats, mice, ${ }^{37}$ and subhuman primates. ${ }^{38}$

Thermal hyperalgesia is the predominant presentation of pain behavior, although both mechanical hyperalgesia and cold allodynia are frequent. Bilateral CCI has been used to model cold hyperalgesia. ${ }^{39}$ Pain behaviors last between 2 weeks to 3 months, depending on the laboratory, ${ }^{28,40,41}$ and was first reported to be exclusively ipsilateral. ${ }^{42}$ However, there are now reports of bilateral pathological pain after $\mathrm{CCI},{ }^{4,44}$ although initial reports indicated only ipsilateral thermal hyperalgesia. Motor deficits parallel loss of peripheral axons, ${ }^{45}$ and motor disturbances and damage to motor axons may extend to the contralateral "noninjured" nerve. ${ }^{46} \mathrm{CCI}$ clearly interrupts local vasculature and blood flow is reduced between the ligatures; thus, CCI also has an ischemic component. ${ }^{47}$ Nerve fiber abnormalities due to ischemia are present within $8.5 \mathrm{~h}^{48}$ Femoral artery ligation or stripping of the epineural vasculature alone also results in thermal hyperalgesia. ${ }^{47}$

Several days after ligature placement, sympathetic efferent fibers grow into the DRG, ${ }^{49}$ and their terminals surround some neuronal somata in a basket-like structure. ${ }^{50}$ This occurs prior to development of pain behavior. ${ }^{49}$ Wallerian degeneration and macrophage infiltration are necessary for sympathetic in-growth; manipulations that either block or delay degeneration also reduce both sympathetic sprouting and pain behavior, ${ }^{51}$ although this has some modality specificity. Guanethidine treatment reduced cold allodynia and thermal sensitivity, and, to a much smaller extent, mechanical hyperalgesia. ${ }^{52,53}$ Pain behavior was first reported to not be influenced by gender, ${ }^{28}$ but others have seen evidence of longer lasting thermal, but not mechanical, hyperalgesia in females and castrated males than in intact males rats. ${ }^{54}$

After CCI, there is an early ipsilateral increase in $\mu$-opioid binding in laminae I to II of the dorsal horn and a bilateral increase in laminae $\mathrm{V}$ and $\mathrm{X}$. All changes are resolved within 10 days postinjury except for the increase in lamina X. Delta and $\kappa$-opioid binding show a 
progressive bilateral postinjury decrease compared to basal. ${ }^{55}$ Backonja et al. ${ }^{56}$ reported that systemic morphine dose dependently reversed thermal hyperalgesia in this model for a 7-day period. This anti-hyperalgesic effect of systemic morphine has been confirmed for cold responses ${ }^{40}$ and paw pressure. ${ }^{57}$ Systemic administration of $\mu, \delta$, and $\kappa$ opiates is associated with reduction of mechanical hyperalgesia. ${ }^{57}$ Interestingly, both $\mu$ and $\kappa$ opiates exert a significant amount of their effects through the peripheral tissue, as injection of receptor specific antagonists into the paw reversed the antihyperalgesia. ${ }^{58}$ Notably, touch-evoked allodynia is insensitive to intravenously administered morphine. ${ }^{59}$ In parallel, intravenously administered morphine does not reduce light touch-evoked Fos, but does reduce heat activated Fos in the dorsal horn in CCI rats. ${ }^{59}$ Intrathecal administration of morphine and oxycodone $(\kappa 2 b)$ produce a reversal of tactile allodynia. ${ }^{60}$ Intrathecal morphine and DPDPE ( $\left[{ }_{D}-P^{-P n^{2}},{ }_{D}-P^{-} n^{5}\right]$-Enkephalin, a $\delta$ opiate agonist), and to a lesser extent U-50 ( $\kappa$ agonist), reversed both thermal hyperalgesia and mechanical allodynia. ${ }^{61,62}$

Pre-emptive treatment of the nerve with lidocaine to block the early injury induced discharge reduces both the duration and magnitude of thermal hyperalgesia. ${ }^{63,64}$ Depot placement of bupivacaine around the sciatic nerve prior to injury, such that development of ectopic activity is blocked for several days, totally prevented the development of the pain behavior. ${ }^{65}$ Low-dose systemic lidocaine, which achieves plasma levels too low to block nerve conduction, reduces ectopic discharge from peripheral neuroma, DRG, and dorsal horn neurons after CCI. ${ }^{66,67}$ Systemic lidocaine effectively reduces cold allodynia and thermal hyperalgesia after CCI, as does its quaternary metabolite, CX-314. ${ }^{40,68,69}$ Systemic administration of amiodarone, a longer acting sodium channel blocker, was also effective in blocking mechanical, thermal, and cold allodynia. ${ }^{70}$ Spinal lidocaine, at doses that work in a variety of other pain models, has been reported to be without effect. ${ }^{71}$ However, Tian et al..$^{72}$ have demonstrated efficacy with higher doses, and thermal sensitivity was more sensitive to lidocaine reversal than was mechanical allodynia. In addition to changes in sodium channel sensitivity, the injured nerve develops a P2receptor mediated sensitivity to ATP. ${ }^{73}$

After CCI in mice, descending noradrenergic innervation of the spinal cord increases. ${ }^{74}$ Systemic clonidine is highly efficacious in blocking cold allodynia in this model. ${ }^{40}$ Intrathecal tizanidine and other $\alpha 2$ adrenergic agonists ${ }^{75}$ are effective in reversing cold and mechanical hyperalgesia ${ }^{76}$ and thermal hyperalgesia. ${ }^{62}$ Pre-emptive systemic clonidine blocks development of mechanical hyperalgesia, ${ }^{77}$ and post-treatment reverses thermal hyperalgesia. $^{78}$

Pre- and post-treatment with systemic nonsedating doses of the dual norpinepherine/serotonin uptake in- hibitor venlafaxine respectively blocks or reverses the development of thermal hyperalgesia. ${ }^{79}$ Intrathecal milnacipran, a newer reuptake inhibitor, was antiallodynic. ${ }^{80}$ Comparatively high doses of amitriptyline block mechanical hyperalgesia. ${ }^{81}$ Intrathecal administration of a chi-conopeptide, Xen2174, reversed mechanoallodynia through a related mechanism as it blocked the norepinephrine transporter. ${ }^{82}$ The maximum effect was better than that achieved with morphine.

\section{Partial sciatic ligation}

The Seltzer or partial sciatic nerve ligation model of neuropathic pain is achieved by tight ligation of approximately one third to one half of the sciatic nerve at the level of the upper thigh, proximal to the sciatic notch. ${ }^{83}$ Variations involving branches of the trigeminal nerve have been successfully developed, ${ }^{84,85}$ and the traditional sciatic version is frequently used in mice. ${ }^{86}$ The plantar surface of the ipsilateral foot develops guarding behavior, whereas bilaterally there is an increased response to repeated Von Frey hair stimulation, heat, and pin prick, suggesting mirror image pain and a strong sympathetic component. Pain behavior is more intense on the side ipsilateral to the injury, ${ }^{87}$ and is said to last for months. ${ }^{88}$ Levels of thermal hyperalgesia are quite variable across different strains of rats (e.g., Lewis rats develop disturbances only in mechanical sensitivity, ${ }^{89}$ whereas Fischer 344 rats develop only thermal allodynia and hyperalgesia ${ }^{90}$ ). Large myelinated fibers are believed to mediate mechanical sensitivity, whereas $\mathrm{C}$ fibers mediate the thermal component. ${ }^{91}$ Accordingly, both extracellular signal-related kinase and Jun $\mathrm{N}$-terminal kinase MAP kinase phosphorylation in astrocytes has been demonstrated in the terminal projection areas of both of these fiber types (i.e., spinal dorsal horn and gracile nucleus).$^{92}$ Gender differences play a large role in this model, and female rats have a significantly higher probability of developing pain behavior than males; this propensity is reversed with ovariectomy. ${ }^{93}$ The location at which estrogen interacts to cause this enhancement is unknown.

Sympathetic fiber sprouting occurs in both the DRG and, to a greater extent, in the gracile nucleus. In the DRG, basket-like structures encircle neurons with both injured and uninjured axons. ${ }^{94}$ Chemical sympathectomy eliminates the mechanical hyperalgesia and $\alpha 2$ antagonists relieve it. ${ }^{95}$

Pre-emptive treatment of the ligation site with lidocaine is ineffective in blocking development of the thermal hyperalgesia. ${ }^{63}$ Systemic lidocaine has no effect, ${ }^{96}$ but equivalent doses of spinal lidocaine are reported to be effective and greatly outlast effects in the sciatic nerve ligation (SNL) model by days. ${ }^{96}$ Intrathecal clonidine is highly effective both as a pre- and post-treatment in relieving tactile hypersensitivity; interestingly, sub-ef- 
fective doses of clonidine are combined with spinal cord stimulation to achieve anti-allodynia with a better side effect profile. ${ }^{97}$ Perineural clonidine at the nerve injury site prevents upregulation of cytokines, particularly tumor necrosis factor along the length of the neuraxis, and mitigates the mechanical allodynia. ${ }^{98,99}$ Tricyclic antidepressants (imiprimine and reuptake inhibitors [paroxetine and milnacipran]) reduce both thermal and mechanical hyperalgesia. ${ }^{86,100}$ Amitriptyline is also effective as a post-treatment against thermal hyperalgesia. $^{101}$

\section{Sciatic nerve ligation}

The third surgical model of neuropathic pain is the SNL model. ${ }^{102}$ The L5 and L6 spinal nerves are tightly ligated just distal to their respective ganglia. Common variations include ligation of only L5, and combining ligation with transection distal to the ligature. All variations are frequently referred to as SNL. The model was first described as having an ipsilateral thermal hyperalgesia lasting more than 1 month and a much longer lasting mechanical allodynia. Guarding behavior develops, which may be indicative of spontaneous pain. Others have described an ipsilateral cold allodynia. More recent articles document a contralateral mechanical and cold allodynia that are delayed and of lesser magnitude than that seen on the ipsilateral side. ${ }^{103}$ Ligation of the spinal nerves is more effective in producing allodynia and guarding behavior in young rats than in old or mature animals. ${ }^{104}$ Transection of the spinal nerves, in addition to ligation, increases the pain behavior in the older animals. ${ }^{105}$ Mechanisms responsible for generation of the causalgia have been debated. One school of thought is that the pain is caused by the intermingling of the injured L5 and L6 fibers, with the intact fibers of the L4 spinal nerve within the sciatic nerve. ${ }^{106,107}$ The idea is that macrophage infiltration and local Schwann cell activation release injury factors that are transported retrogradely to the cell bodies of the L4 ganglia. Certainly, the SNL injury results in MAP kinase activation in the L4 DRG, and chemical sensitization and ectopic activation of L4 neurons. ${ }^{108-110}$ Transection of the L5 ventral root, which results in Wallerian degeneration of large myelinated axons within the sciatic nerve, also causes allodynia of several weeks duration. ${ }^{111,112}$

Pain behavior resulting from SNL is reported to be sympathetically maintained as surgical sympathectomy permanently and sympathetic block by adrenergic antagonists reversibly causes a cessation of mechanical and cold allodynia. ${ }^{113,114}$ In addition, SNL induces sympathetic sprouting into the dorsal root ganglia. ${ }^{115}$ However, the sympathetic component of the model has been disputed, ${ }^{116}$ and the belief now is that the sympathetic component is influenced by not only the strain, but also, perhaps, by the vendor-dependent substrain. ${ }^{117}$ Variables affecting ligation-evoked changes in pain thresholds have included gender. In this respect, autotomy differs from partial nerve ligation-induced neuropathy, because the incidence of allodynia after spinal nerve ligation is higher in female than male rats. ${ }^{118}$ However, this observation may be influenced by strain, because female Sprague-Dawley but not Holtzman rats are reported to develop greater mechanical allodynia than their male counterparts. ${ }^{119}$

Systemic, but not local, lidocaine works effectively to reverse tactile allodynia arising from SNL. ${ }^{120}$ Systemic administration of fluphenazine, an anti-psychotic that also blocks $\mathrm{Na}+$ channels, reduces ectopic activity in afferent fibers and reverses mechanical allodynia. ${ }^{121}$ Strichartz reports that intravenously administered lidocaine produces a partial but permanent reversal (plasma levels, $2.1 \mathrm{ug} / \mathrm{mL}$ plasma) of ipsilateral allodynia, whereas lower plasma levels resulted in a temporary reversal only. Contralateral allodynia, in this model, is reversed only acutely by intravenously administered lidocaine at even the highest plasma levels. ${ }^{87}$ In contrast to the lack of efficacy of spinal lidocaine on SNL-induced allodynia, reported by Chaplan, spinal mexiletene reduces $\mathrm{A} \delta$ and $\mathrm{C}$ fiber and von Frey hair-evoked responses in SNL, but not sham animals, ${ }^{122}$ and anti-allodynia of spinal lidocaine is reported by others. ${ }^{96}$ Interestingly, continuous systemic lidocaine started before the lesion reduces sympathetic sprouting into the L5 DRG. ${ }^{123}$ This effect lasted more than a week after cessation of treatment.

Systemic (intraperitoneal) and intracerebroventricular morphine completely reverse mechanical allodynia generated by SNL. ${ }^{124,125}$ This has been shown to be specific for the static component of allodynia (maintained application of von Frey filaments) and not for withdrawal evoked by a more dynamic stimulus (stroking with a cotton applicator). ${ }^{126}$ In contrast, Kontinen et al. ${ }^{127}$ has reported no effect of systemic morphine, administered either pre-emptively or as a continuous post-treatment, on either mechanical or cold allodynia. Intrathecal administration of $\mu, \delta$, and $\kappa$ agonists are reported to be without effect on mechanoallodynia. ${ }^{125}$ However, in electrophysiological studies, systemic morphine was less effective than morphine administered via direct spinal application in the inhibition of C-fiber, heat, and mechanical stimulation-evoked activity in dorsal horn neurons $^{128}$ and intrathecal administration of morphine has been shown to be effective in reversing mechanical allodynia. ${ }^{129}$

Intrathecal $\alpha 2$ agonists reverse SNL-induced mechanical allodynia. ${ }^{130}$ This is substantiated by recent work indicating that intrathecal $\alpha 2$ agonists exacerbate thermal hyperalgesia after SNL. ${ }^{131}$ Chronic treatment with the tricyclic antidepressants (desipramine and milnacipran) attenuate mechanical and thermal allodynia. ${ }^{132,133}$ Acute treatment with milnacipran is effective in reversing ther- 
mal, but not mechanical sensitization. ${ }^{133}$ Spinal administration of Xen2174 produces similar results to CCI.

The spared nerve injury ${ }^{19}$ model is a lesion of the tibial and common peroneal nerves, but spares the sural nerve. This permits testing of skin containing no injured or degenerating fibers. Thus, it does not result in close proximity of injured and degenerating fibers with intact axons in the periphery, although mixing does occur more proximally in the sciatic nerve. The spared nerve injury model produces an increased ipsilateral response to mechanical (both low- and high-threshold) and thermal (hot and cold) stimuli within the sural distribution, and to a lesser extent within the saphenous veins, which lasts more than 6 months. ${ }^{19}$ The mechanical allodynia is more prominent in hairy skin. ${ }^{129}$ Strain differences influence the extent of the pain behavior (Lewis rats are least affected), but all strains exhibit mechanical sensitivity. ${ }^{134}$ Late sprouting of sympathetic fibers into the DRG is documented at 8 weeks post-injury, resulting in basket structures around the neuronal stomata. ${ }^{94,135}$ Surgical sympathectomy has no effect on either mechanical allodynia or hyperalgesia, ${ }^{135,136}$ but greatly attenuates the cold allodynia. ${ }^{136}$

Systemic morphine dose dependently reduces mechanical allodynia and hyperalgesia, as well as cold allodynia. ${ }^{129,134,137}$ Spinal morphine is also effective in blocking mechanical allodynia. ${ }^{129,134}$ However, Decosterd et al. ${ }^{138}$ found that systemic morphine, amitriptyline, and carbamazepine produced only modest reversal of mechanical and cold allodynia.

Early and sustained blockade of peripheral nerve activity with bupivacaine for 1 week or more does not block development of spared nerve injury; this points to an initiating mechanism other than an afferent barrage of neural activity. ${ }^{139}$ In rats, systemic administration of lidocaine and lamotrigine, as well as moderate doses of tocainide $(50 \mathrm{mg} / \mathrm{kg})$, has no effect of mechanical or cold allodynia or mechanical hyperalgesia; however, higher doses of tocainide $(75 \mathrm{mg} / \mathrm{kg})$ and mexiletine $(37.5 \mathrm{mg} / \mathrm{kg})$ successfully reverse sensitivity to both mechanical and cold allodynia. ${ }^{140,141}$ Lamotrigine (30 and $60 \mathrm{mg} / \mathrm{kg}$ ) and tocainide (50 and $75 \mathrm{mg} / \mathrm{kg}$ ) are both able to reverse mechanical hyperalgesia. ${ }^{141}$ Systemic fluphenazine attenuates tactile allodynia and blocks ectopic discharge in primary afferent fibers, presumably through its ability to block $\mathrm{Na}^{+}$channels. ${ }^{121}$

\section{PLEXUS AVULSION}

Plexus avulsions are surprisingly common after upper torso injuries and typically result in severe pain states. ${ }^{142}$ Unilateral avulsion of the brachial plexus in male Wistar rats produced a long-lasting (through 90 days) bilateral cold and mechanical allodynia with no change in locomotor activity. ${ }^{143}$ In subsequent work, this group re- ported that systemic morphine, clonidine, ketamine, or gabapentin reduced both mechanical and cold allodynia. Celecoxib blocked mechanical allodynia, but not cold allodynia, whereas lidocaine attenuated only cold allodynia. Diclofenac, dexamethasone, or imipramine had no effect. $^{143}$

\section{Nerve ischemia models}

There are several models of nerve ischemia generally performed on the sciatic nerve. Wiesenfeld-Hallin and colleagues developed an interesting version of photochemically induced ischemia on the rat ${ }^{144-146}$ and mouse ${ }^{147}$ that involves intravenous injection of erythrosine $\mathrm{B}$, a photosensitizing dye, followed by exposure of a length of the sciatic nerve and irradiating it with an argon ion laser for a proscribed period of time. This results in long-lasting (up to 28 days for some modalities) bilateral mechanical and cold allodynia and unilateral thermal hyperalgesia. In general, ipsilateral pathological pain behavior was of greater magnitude than contralateral, and the onset was faster. Approximately $95 \%$ of the animals develop pathological pain. Rats, but not mice, display signs of spontaneous pain. ${ }^{146,147}$ Damage to myelinated axons and Wallerian degeneration in ipsilateral nerve is extensive, accompanied by macrophage infiltration and phagocytosis of Schwann cells. Normal Remak bundles of unmyelinated axons are disturbed with only isolated axons remaining. The contralateral nerve displays no axonal injury or immune cell infiltrate. Despite the fact that the extent of sciatic nerve damage is the same after focal ischemia in several strains of rat, genetic strain greatly affects development of pain behavior. ${ }^{148}$ Extent of nerve injury and behavioral abnormalities are dependent on the duration of exposure to the laser. ${ }^{146}$ After resolution of pain behavior, all fiber types regenerate. ${ }^{149}$ Spinal morphine dose dependently inhibits mechanical and cold allodynia, and spinal clonidine reverses hypersensitivity to cold but not mechanical stimulation. ${ }^{145}$

A major variation of sciatic nerve ischemia is hindpaw ischemia and reperfusion. This induces long-lasting bilateral mechanical allodynia and hyperalgesia, as well as sensitivity to cold. ${ }^{150}$ Mechanical allodynia in this model within a few days of the injury can be reversed by systemic administration of sympathetic antagonists, such as guanethidine, phentolamine, clonidine, and prazo$\sin .{ }^{151}$ These treatments become ineffective several days after the insult.

\section{INJURY TO THE DRG}

In humans, herniated discs or spinal stenoses, which compress the adjacent root and DRG, can evoke paresthesias and leg pain. ${ }^{152}$ Mechanisms underlying this pain state are complex, but reflect the mechanical and chemical sensitivity of the DRG. Thus, the DRG, unlike the 
peripheral axon, has the ability to respond in a graded fashion to mechanical distortion and to display persistent activation secondary to the local release or application of a variety of pro-inflammatory chemicals, such as prostaglandins, kinins, amines and cytokines. Compression injury of the DRG leads to ongoing ectopic activity. ${ }^{153-155}$ Similarly, avulsion of the disc can lead to the local release of disc products from the injured disc. Application of nucleus pulposus products will initiate discharge in the DRG. Furthermore, studies specifically examining delivery of a pro-inflammatory product to the previously compressed DRG yield an enhanced electrophysiological response in DRG neurons. ${ }^{156}$

\section{Compression of the DRG/root}

Metal rods placed into the intervertebral foramen at L4 and/or L5 produced a thermal hyperalgesia and cold and tactile allodynia during an extended 35-day postoperative period. The tactile allodynia corresponds with the ability of a cotton wisp to evoke a reflex withdrawal of the hind paw. Sham surgeries were without persisting effects. ${ }^{157,158}$ Both unilateral and bilateral effects have been reported. An alternate method is to use an epidural catheter and a nylon rod. ${ }^{159}$ The spontaneous activity of injured DRG cells is blocked by gabapentin without interrupting spike transmission.

\section{LAMINECTORY}

After laminectomy, pain of the lower back along with sciatica is frequently noted. In rats, a lumbar laminectomy resulted in 8 weeks of paraspinous muscle spasm, tail contracture, pain behavior, and tactile allodynia. These observations correlated with epidural and nerve root scarring, and nerve root adherence to the associated disc and adjacent pedicle. ${ }^{160}$

\section{DISC INJURY}

Annular tears in an intervertebral disc have been found to correlate with low back pain in human patients. ${ }^{161,162}$ The mechanism of this pain state is not certain. Annular injury may reflect activation of local sensory receptors in the annulus or the sprouting of sensory axons into the disc. Puncture of the L4 to L5 discs resulted in increases in defined pain behaviors, including "grooming" and "wet-dog shakes." 163,164 Consistent with the role of active factors arising from the ruptured disc, a behavioral model has been developed wherein autologous nucleus pulposus is placed onto the L5 DRG exposed by unilateral facetectomy. This treatment resulted in marked ambulatory asymmetry and a preference to bear weight on the contralateral limb at extended intervals after treatment. ${ }^{165}$

\section{CONCLUSION}

In the past 30 years, it has become increasingly appreciated that mechanisms underlying pain states associated with nerve injury (e.g., painful neuropathies) may well mediate a variety of pain states arising from a wide variety of stimulus/treatment conditions. Thus, it is appreciated that frank nerve injury will lead to a variety of changes in the biology of the dorsal root ganglion cells of the injured axon, such as, for example, an increase in the expression of DRG activation transcription factor-3. ${ }^{166}$ In this regard, changes in DRG activation transcription factor-3 expression have been observed not only after nerve section and compression, but after chemical stimuli (paclitaxel ${ }^{135}$ ), in diabetes, ${ }^{167}$ and even in some peripheral chronic inflammatory syndromes as diverse as equine laminitis. ${ }^{168}$ It is thus reasonable to expect that many of these chronic states may lead to changes in nerve function that lead to the encoding of a nociceptive signal.

Acknowledgments: This activity was supported by the United States National Institutes of Health by grant no. NS0485563 (LS), grant no. DA0110 (TY), and grant no. NS16541 (TY).

\section{REFERENCES}

1. Sunderland S. Nerves and nerve injuries. Edinburgh London: Churchill Livingstone, 1972.

2. Weir-Mitchell S, Moorhouse GR, Keen WW. Gunshot wounds and other injuries of nerves. Philadephia: Lippincott, 1864.

3. Campbell JN, Meyer RA. Mechanisms of neuropathic pain. Neuron 2006;52:77-92.

4. Zimmermann M. Pathobiology of neuropathic pain. Eur J Pharmacol 2001;429:23-37.

5. Schoffnegger D, Ruscheweyh R, Sandkuhler J. Spread of excitation across modality borders in spinal dorsal horn of neuropathic rats. Pain 2008;135:300-310.

6. Backonja M, Glanzman RL. Gabapentin dosing for neuropathic pain: evidence from randomized, placebo-controlled clinical trials. Clin Ther 2003;25:81-104.

7. Gold MS. Sodium channels and pain therapy. Curr Opin Anaesthesiol 2000;13:565-572.

8. Saarto T, Wiffen PJ. Antidepressants for neuropathic pain. Cochrane Database Syst Rev 2007:CD005454.

9. Eisenberg E, McNicol ED, Carr DB. Efficacy of mu-opioid agonists in the treatment of evoked neuropathic pain: systematic review of randomized controlled trials. Eur J Pain 2006;10:667676.

10. Nicholson B. Benefits of extended-release opioid analgesic formulations in the treatment of chronic pain. Pain Pract 2009;9: 71-81.

11. Raber P, Devor M. Social variables affect phenotype in the neuroma model of neuropathic pain. Pain 2002;97:139-150.

12. Chesler EJ, Wilson SG, Lariviere WR, Rodriguez-Zas SL, Mogil JS. Identification and ranking of genetic and laboratory environment factors influencing a behavioral trait, thermal nociception, via computational analysis of a large data archive. Neurosci Biobehav Rev 2002;26:907-923.

13. Vissers K, De Jongh R, Hoffmann V, Heylen R, Crul B, Meert T. Internal and external factors affecting the development of neuropathic pain in rodents. Is it all about pain? Pain Pract 2003;3: 326-342. 
14. Wall PD, Devor M, Inbal R, et al. Autotomy following peripheral nerve lesions: experimental anaesthesia dolorosa. Pain 1979;7: 103-111.

15. Attal N, Filliatreau G, Perrot S, Jazat F, Di Giamberardino L, Guilbaud G. Behavioural pain-related disorders and contribution of the saphenous nerve in crush and chronic constriction injury of the rat sciatic nerve. Pain 1994;59:301-312.

16. DeLeo JA, Coombs DW, Willenbring S, et al. Characterization of a neuropathic pain model: sciatic cryoneurolysis in the rat. Pain 1994;56:9-16.

17. Levitt M. Dysesthesias and self-mutilation in humans and subhumans: a review of clinical and experimental studies. Brain Res 1985;357:247-290.

18. Walczak JS, Pichette V, Leblond F, Desbiens K, Beaulieu P. Behavioral, pharmacological and molecular characterization of the saphenous nerve partial ligation: a new model of neuropathic pain. Neuroscience 2005;132:1093-1102.

19. Decosterd I, Woolf CJ. Spared nerve injury: an animal model of persistent peripheral neuropathic pain. Pain 2000;87:149-158.

20. Hofmann HA, De Vry J, Siegling A, Spreyer P, Denzer D. Pharmacological sensitivity and gene expression analysis of the tibial nerve injury model of neuropathic pain. Eur J Pharmacol 2003; 470:17-25.

21. Coderre TJ, Grimes RW, Melzack R. Deafferentation and chronic pain in animals: an evaluation of evidence suggesting autotomy is related to pain. Pain 1986;26:61-84.

22. Blumenkopf B, Lipman JJ. Studies in autotomy: its pathophysiology and usefulness as a model of chronic pain. Pain 1991;45: 203-209.

23. Wagner R, DeLeo JA, Coombs DW, Myers RR. Gender differences in autotomy following sciatic cryoneurolysis in the rat. Physiol Behav 1995;58:37-41.

24. Inbal R, Devor M, Tuchendler O, Lieblich I. Autotomy following nerve injury: genetic factors in the development of chronic pain. Pain 1980;9:327-337.

25. Devor M, Raber P. Heritability of symptoms in an experimental model of neuropathic pain. Pain 1990;42:51-67.

26. Zeltser R, Beilin B, Zaslansky R, Seltzer Z. Comparison of autotomy behavior induced in rats by various clinically-used neurectomy methods. Pain 2000;89:19-24.

27. Dowdall T, Robinson I, Meert TF. Comparison of five different rat models of peripheral nerve injury. Pharmacol Biochem Behav 2005;80:93-108.

28. Bennett GJ, Xie YK. A peripheral mononeuropathy in rat that produces disorders of pain sensation like those seen in man [see comments]. Pain 1988;33:87-107.

29. Maves TJ, Pechman PS, Gebhart GF, Meller ST. Possible chemical contribution from chronic-gut sutures produces disorders of pain sensation like those seen in man. Pain 1993;54:57-69.

30. Carlton SM, Dougherty PM, Pover CM, Coggeshall RE. Neuroma formation and numbers of axons in a rat model of experimental peripheral neuropathy. Neurosci Lett 1991;131:88-92.

31. Kajander KC, Bennett GJ. Onset of a painful peripheral neuropathy in rat: a partial and differential deafferentation and spontaneous discharge in A beta and A delta primary afferent neurons. J Neurophysiol 1992;68:734-744.

32. Sommer C, Lalonde A, Heckman HM, Rodriguez M, Myers RR. Quantitative neuropathology of a focal nerve injury causing hyperalgesia. J Neuropath Exp Neurol 1995;54:635-643.

33. Myers RR, Heckman HM, Rodriguez M. Reduced hyperalgesia in nerve-injured WLD mice: Relationship to nerve fiber phagocytosis, axonal degeneration and regeneration in normal mice. Exptl Neurol 1996;141:94-101.

34. Grelik C, Bennett GJ, Ribeiro-da-Silva A. Autonomic fibre sprouting and changes in nociceptive sensory innervation in the rat lower lip skin following chronic constriction injury. Eur J Neurosci 2005;21:2475-2487.

35. Vos BP, Benoist JM, Gautron M, Guilbaud G. Changes in neuronal activities in the two ventral posterior medial thalamic nuclei in an experimental model of trigeminal pain in the rat by constriction of one infraorbital nerve. Somatosens Mot Res 2000;17: $109-122$.
36. Kitagawa J, Takeda M, Suzuki I, et al. Mechanisms involved in modulation of trigeminal primary afferent activity in rats with peripheral mononeuropathy. Eur J Neurosci 2006;24:1976-1986.

37. Sommer C, Schmidt C, George A, Toyka KV. A metalloproteaseinhibitor reduces pain associated behavior in mice with experimental neuropathy. Neurosci Lett 1997;237:45-48.

38. Carlton SM, Lekan HA, Kim SH, Chung JM. Behavioral manifestations of an experimental model for peripheral neuropathy produced by spinal nerve ligation in the primate. Pain 1994;56: 155-166.

39. Vierck CJ, Acosta-Rua AJ, Johnson RD. Bilateral chronic constriction of the sciatic nerve: a model of long-term cold hyperalgesia. J Pain 2005;6:507-517.

40. Jasmin L, Kohan L, Franssen M, Janni G, Goff JR. The cold plate as a test of nociceptive behaviors: description and application to the study of chronic neuropathic and inflammatory pain models. Pain 1998;75:367-382.

41. Covey WC, Ignatowski TA, Renauld AE, Knight PR, Nader ND, Spengler RN. Expression of neuron-associated tumor necrosis factor alpha in the brain is increased during persistent pain. Reg Anesth Pain Med 2002;27:357-366.

42. Vogel C, Mossner R, Gerlach M, et al. Absence of thermal hyperalgesia in serotonin transporter-deficient mice. J Neurosci 2003;23:708-715.

43. Hutchinson MR, Zhang Y, Brown K, et al. Non-stereoselective reversal of neuropathic pain by naloxone and naltrexone: involvement of toll-like receptor 4 (TLR4). Eur J Neurosci 2008;28: 20-29.

44. Milligan ED, Sloane EM, Langer SJ, et al. Controlling neuropathic pain by adeno-associated virus driven production of the anti-inflammatory cytokine, interleukin-10. Mol Pain 2005;1:9.

45. Kingery WS, Lu JD, Roffers JA, Kell DR. The resolution of neuropathic hyperalgesia following motor and sensory functional recovery in sciatic axonotmetic mononeuropathies. Pain 1994;58: 157-168.

46. Bullens P, Daemen M, Freling G, Kitslaar P, Van den Wildenberg F, Kurvers H. Motor dysfunction and reflex sympathetic dystrophy. Bilateral motor denervation in an experimental model. Acta Orthop Belg 1998;64:218-223.

47. Myers RR, Yamamoto T, Yaksh TL, Powell HC. The role of focal nerve ischemia and Wallerian degeneration in peripheral nerve injury producing hyperesthesia. Anesthesiology 1993;78:308316.

48. Jacobs JM, Ro LS. A morphological study of experimental mononeuropathy in the rat: early ischemic changes. J Neurol Sci 1994;127:143-152.

49. Ramer MS, Bisby MA. Rapid sprouting of sympathetic axons in dorsal root ganglia of rats with a chronic constriction injury. Pain 1997; 70:237-244.

50. McLachlan EM, Janig W, Devor M, Michaelis M. Peripheral nerve injury triggers noradrenergic sprouting within dorsal root ganglia. Nature 1993;363:543-546.

51. Ramer MS, French GD, Bisby MA. Wallerian degeneration is required for both neuropathic pain and sympathetic sprouting into the DRG. Pain 1997;72:71-78.

52. Neil A, Attal N, Guilbaud G. Effects of guanethidine on sensitization to natural stimuli and self-mutilating behaviour in rats with a peripheral neuropathy. Brain Res 1991;565:237-246.

53. Perrot S, Attal N, Ardid D, Guilbaud G. Are mechanical and cold allodynia in mononeuropathic and arthritic rats relieved by systemic treatment with calcitonin or guanethidine? Pain 1993;52: 41-47.

54. Tall JM, Stuesse SL, Cruce WL, Crisp T. Gender and the behavioral manifestations of neuropathic pain. Pharmacol Biochem Behav 2001;68:99-104.

55. Stevens CW, Kajander KC, Bennett GJ, Seybold VS. Bilateral and differential changes in spinal mu, delta and kappa opioid binding in rats with a painful, unilateral neuropathy. Pain 1991; 46:315-326.

56. Backonja MM, Miletic G, Miletic V. The effect of continuous morphine analgesia on chronic thermal hyperalgesia due to sciatic constriction injury in rats. Neurosci Lett 1995;196:61-64.

57. Catheline G, Kayser V, Idanpaan-Heikkila JJ, Guilbaud G. The 
antinociceptive activity of kappa- but not delta-opioid receptor agonists is maintained in morphine-tolerant neuropathic rats. Eur J Pharmacol 1996;318:273-281.

58. Catheline G, Kayser V, Guilbaud G. Further evidence for a peripheral component in the enhanced antinociceptive effect of systemic morphine in mononeuropathic rats: involvement of kappa-, but not delta-opioid receptors. Eur J Pharmacol 1996;315: 135-143.

59. Catheline G, Le Guen S, Besson JM. Intravenous morphine does not modify dorsal horn touch-evoked allodynia in the mononeuropathic rat: a Fos study. Pain 2001;92:389-398.

60. Nielsen CK, Ross FB, Lotfipour S, Saini KS, Edwards SR, Smith MT. Oxycodone and morphine have distinctly different pharmacological profiles: radioligand binding and behavioural studies in two rat models of neuropathic pain. Pain 2007;132:289-300.

61. Leiphart JW, Dills CV, Zikel OM, Kim DL, Levy RM. A comparison of intrathecally administered narcotic and nonnarcotic analgesics for experimental chronic neuropathic pain. J Neurosurg 1995;82:595-599.

62. Yamamoto T, Yaksh TL. Spinal pharmacology of thermal hyperesthesia induced by incomplete ligation of sciatic nerve. I. Opioid and nonopioid receptors. Anesthesiology 1991;75:817-826.

63. Dougherty PM, Garrison CJ, Carlton SM. Differential influence of local anesthetic upon two models of experimentally induced peripheral mononeuropathy in the rat. Brain Res 1992;570:109-115.

64. Sotgiu ML, Castagna A, Lacerenza M, Marchettini P. Pre-injury lidocaine treatment prevents thermal hyperalgesia and cutaneous thermal abnormalities in a rat model of peripheral neuropathy. Pain 1995;61:3-10.

65. Xie W, Strong JA, Meij JT, Zhang JM, Yu L. Neuropathic pain: early spontaneous afferent activity is the trigger. Pain $2005 ; 116$ : 243-256.

66. Sotgiu ML, Biella G, Castagna A, Lacerenza M, Marchettini P. Different time-courses of i.v. lidocaine effect on ganglionic and spinal units in neuropathic rats. Neuroreport 1994;5:873-876.

67. Omana-Zapata I, Khabbaz MA, Hunter JC, Bley KR. QX-314 inhibits ectopic nerve activity associated with neuropathic pain. Brain Research 1997;771:228-237.

68. Smith LJ, Shih A, Miletic G, Miletic V. Continual systemic infusion of lidocaine provides analgesia in an animal model of neuropathic pain. Pain 2002;97:267-273.

69. Abram SE, Yaksh TL. Systemic lidocaine blocks nerve injuryinduced hyperalgesia and nociceptor-driven spinal sensitization in the rat. Anesthesiology 1994;80:383-391.

70. Datta S, Waghray T, Torres M, Glusman S. Amiodarone decreases heat, cold, and mechanical hyperalgesia in a rat model of neuropathic pain. Anesth Analg 2004;98:178-184.

71. Cui JC, Linderoth B, Meyerson BA. Incidence of mononeuropathy in rats is influenced by pre-emptive alteration of spinal excitability. Eur J Pain 1997;1:53-59.

72. Tian J, Gu Y, Su D, Wu Y, Wang X. Effects of intrathecal lidocaine on hyperalgesia and allodynia following chronic constriction injury in rats. Eur J Pain 2009;13:130-137.

73. Chen Y, Shu Y, Zhao Z. Ectopic purinergic sensitivity develops at sites of chronic nerve constriction injury in rat. Neuroreport 1999; 10:2779-2782.

74. Ma W, Eisenach JC. Chronic constriction injury of sciatic nerve induces the up-regulation of descending inhibitory noradrenergic innervation to the lumbar dorsal horn of mice. Brain Res 2003; 970:110-118.

75. Leiphart JW, Dills CV, Levy RM. Alpha2-adrenergic receptor subtype specificity of intrathecally administered tizanidine used for analgesia for neuropathic pain. J Neurosurg 2004;101:641647.

76. Levy R, Leiphart J, Dills C. Analgesic action of acute and chronic intraspinally administered opiate and alpha 2-adrenergic agonists in chronic neuropathic pain. Stereotact Funct Neurosurg 1994;62: 279-289.

77. Munglani R, Bond A, Smith GD, et al. Changes in neuronal markers in a mononeuropathic rat model relationship between neuropeptide Y, pre-emptive drug treatment and long-term mechanical hyperalgesia. Pain 1995;63:21-31.

78. Hord AH, Denson DD, Stowe B, Haygood RM. alpha-1 and alpha-2 adrenergic antagonists relieve thermal hyperalgesia in experimental mononeuropathy from chronic constriction injury. Anesth Analg 2001;92:1558-1562.

79. Lang E, Hord AH, Denson D. Venlafaxine hydrochloride (Effexor) relieves thermal hyperalgesia in rats with an experimental mononeuropathy. Pain 1996;68:151-155.

80. Ikeda T, Ishida Y, Naono R, et al. Effects of intrathecal administration of newer antidepressants on mechanical allodynia in rat models of neuropathic pain. Neurosci Res 2009;63:42-46.

81. Yasuda $\mathrm{T}$, Iwamoto $\mathrm{T}$, Ohara $\mathrm{M}$, et al. The novel analgesic compound OT-7100 (5-n-butyl-7-(3,4,5-trimethoxybenzoylamino) pyrazolo[1,5-a]pyrimid ine) attenuates mechanical nociceptive responses in animal models of acute and peripheral neuropathic hyperalgesia. Jpn J Pharmacol 1999;79:65-73.

82. Nielsen CK, Lewis RJ, Alewood D, et al. Anti-allodynic efficacy of the chi-conopeptide, Xen2174, in rats with neuropathic pain. Pain 2005;118:112-124.

83. Seltzer Z, Dubner R, Shir Y. A novel behavioral model of neuropathic pain disorders produced in rats by partial sciatic nerve injury. Pain 1990;43:205-218.

84. Xu M, Aita M, Chavkin C. Partial infraorbital nerve ligation as a model of trigeminal nerve injury in the mouse: behavioral, neural, and glial reactions. J Pain 2008;9:1036-1048.

85. Shinoda M, Kawashima K, Ozaki N, Asai H, Nagamine K, Sugiura Y. P2X3 receptor mediates heat hyperalgesia in a rat model of trigeminal neuropathic pain. J Pain 2007;8:588-597.

86. Matsuzawa-Yanagida K, Narita M, Nakajima M, et al. Usefulness of antidepressants for improving the neuropathic pain-like state and pain-induced anxiety through actions at different brain sites. Neuropsychopharmacology 2008;33:1952-1965.

87. Sinnott CJ, Garfield JM, Strichartz GR. Differential efficacy of intravenous lidocaine in alleviating ipsilateral versus contralateral neuropathic pain in the rat. Pain 1999;80:521-531.

88. Seltzer Z, Shir Y. Sympathetically-maintained causalgiform disorders in a model for neuropathic pain: a review. J Basic Clin Physiol Pharmacol 1991;2:17-61.

89. Shir Y, Seltzer Z. Heat hyperalgesia following partial sciatic ligation in rats: interacting nature and nurture. Neuroreport 2001; $12: 809-813$.

90. Fecho K, Valtschanoff JG. Acute inflammatory and neuropathic pain in Lewis and Fischer rats. J Neuroendocrinol 2006;18:504513.

91. Shir Y, Seltzer Z. A-fibers mediate mechanical hyperesthesia and allodynia and $\mathrm{C}$-fibers mediate thermal hyperalgesia in a new model of causalgiform pain disorders in rats. Neuroscience Letters 1990;115:62-67.

92. Ma W, Quirion R. Partial sciatic nerve ligation induces increase in the phosphorylation of extracellular signal-regulated kinase (ERK) and c-Jun N-terminal kinase (JNK) in astrocytes in the lumbar spinal dorsal horn and the gracile nucleus. Pain 2002;99: 175-184.

93. Coyle DE. Partial peripheral nerve injury leads to activation of astroglia and microglia which parallels the development of allodynic behavior. Glia 1998;23:75-83.

94. Ma W, Bisby MA. Partial sciatic nerve transection induced tyrosine hydroxidase immunoreactive axon sprouting around both injured and spared dorsal root ganglion neurons which project to the gracile nucleus in middle-aged rats. Neurosci Lett 1999;275: $117-120$.

95. Tracey DJ, Cunningham JE, Romm MA. Peripheral hyperalgesia in experimental neuropathy: mediation by alpha 2-adrenoreceptors on post-ganglionic sympathetic terminals. Pain 1995;60:317327.

96. Ma W, Du W, Eisenach JC. Intrathecal lidocaine reverses tactile allodynia caused by nerve injuries and potentiates the antiallodynic effect of the COX inhibitor ketorolac. Anesthesiology 2003;98:203-208.

97. Schechtmann G, Wallin J, Meyerson BA, Linderoth B. Intrathecal clonidine potentiates suppression of tactile hypersensitivity by spinal cord stimulation in a model of neuropathy. Anesth Analg 2004;99:135-139.

98. Lavand'homme PM, Eisenach JC. Perioperative administration of the alpha2-adrenoceptor agonist clonidine at the site of nerve 
injury reduces the development of mechanical hypersensitivity and modulates local cytokine expression. Pain 2003;105: 247-254.

99. Lavand'homme PM, Ma W, De Kock M, Eisenach JC. Perineural alpha(2A)-adrenoceptor activation inhibits spinal cord neuroplasticity and tactile allodynia after nerve injury. Anesthesiology 2002;97:972-980.

100. Hota D, Bansal V, Pattanaik S. Evaluation of ketamine, nimodipine, gabapentin and imipramine in partial sciatic nerve transection model of neuropathic pain in rat: an experimental study. Methods Find Exp Clin Pharmacol 2007;29:443-446.

101. McCarson KE, Ralya A, Reisman SA, Enna SJ. Amitriptyline prevents thermal hyperalgesia and modifications in rat spinal cord $\mathrm{GABA}(\mathrm{B})$ receptor expression and function in an animal model of neuropathic pain. Biochem Pharmacol 2005;71:196-202.

102. Kim SH, Chung JM. An experimental model for peripheral neuropathy produced by segmental spinal nerve ligation in the rat. Pain 1992;50:355-363.

103. Arguis MJ, Perez J, Martinez G, Ubre M, Gomar C. Contralateral neuropathic pain following a surgical model of unilateral nerve injury in rats. Reg Anesth Pain Med 2008;33:211-216.

104. Chung JM, Choi Y, Yoon YW, Na HS. Effects of age on behavioral signs of neuropathic pain in an experimental rat model. Neurosci Lett 1995;183:54-57.

105. Svensson C, Schaefers M, Jones TL, Powell HC, Yaksh TL, Sorkin LS. Age dependent change in allodynia and p38 MAPK activation following spinal nerve ligation. J Pain 2004;5(suppl 1):33.

106. Wu G, Ringkamp M, Murinson BB, et al. Degeneration of myelinated efferent fibers induces spontaneous activity in uninjured C-fiber afferents. J Neurosci 2002;22:7746-7753.

107. Ali Z, Ringkamp M, Hartke TV, et al. Uninjured C-fiber nociceptors develop spontaneous activity and alpha-adrenergic sensitivity following L6 spinal nerve ligation in monkey. J Neurophysiol 1999;81:455-466.

108. Schafers M, Sommer C, Geis C, Hagenacker T, Vandenabeele P, Sorkin LS. Selective stimulation of either tumor necrosis factor receptor differentially induces pain behavior in vivo and ectopic activity in sensory neurons in vitro. Neuroscience 2008; 157:414423.

109. Obata K, Yamanaka H, Dai Y, et al. Contribution of degeneration of motor and sensory fibers to pain behavior and the changes in neurotrophic factors in rat dorsal root ganglion. Exp Neurol 2004; 188:149-160.

110. Obata K, Yamanaka H, Kobayashi K, et al. Role of mitogenactivated protein kinase activation in injured and intact primary afferent neurons for mechanical and heat hypersensitivity after spinal nerve ligation. J Neurosci 2004;24:10211-10222.

111. Sheth RN, Dorsi MJ, Li Y, et al. Mechanical hyperalgesia after an L5 ventral rhizotomy or an L5 ganglionectomy in the rat. Pain 2002;96:63-72.

112. Li L, Xian CJ, Zhong JH, Zhou XF. Lumbar 5 ventral root transection-induced upregulation of nerve growth factor in sensory neurons and their target tissues: a mechanism in neuropathic pain. Mol Cell Neurosci 2003;23:232-250.

113. Kim SH, Na HS, Sheen K, Chung JM. Effects of sympathectomy on a rat model of peripheral neuropathy. Pain 1993;55:85-92.

114. Choi Y, Yoon YW, Na HS, Kim SH, Chung JM. Behavioral signs of ongoing pain and cold allodynia in a rat model of neuropathic pain. Pain 1994;59:369-376.

115. Chung K, Lee BH, Yoon YW, Chung JM. Sympathetic sprouting in the dorsal root ganglia of the injured peripheral nerve in a rat neuropathic pain model. J Comp Neurol 1996;376:241-252.

116. Ringkamp M, Eschenfelder S, Grethel EJ, et al. Lumbar sympathectomy failed to reverse mechanical allodynia- and hyperalgesia-like behavior in rats with L5 spinal nerve injury. Pain 1999; 79:143-153.

117. Yoon YW, Lee DH, Lee BH, Chung K, Chung JM. Different strains and substrains of rats show different levels of neuropathic pain behaviors. Exp Brain Res 1999;129:167-171.

118. Coyle DE, Sehlhorst CS, Behbehani MM. Intact female rats are more susceptible to the development of tactile allodynia than ovariectomized female rats following partial sciatic nerve ligation (PSNL). Neurosci Lett 1996;203:37-40.

119. DeLeo JA, Rutkowski MD. Gender differences in rat neuropathic pain sensitivity is dependent on strain. Neurosci Lett 2000;282: 197-199.

120. Chaplan SR, Bach FW, Shafer SL, Yaksh TL. Prolonged alleviation of tactile allodynia by intravenous lidocaine in neuropathic rats [see comments]. Anesthesiology 1995;83:775-785.

121. Dong XW, Jia Y, Lu SX, et al. The antipsychotic drug, fluphenazine, effectively reverses mechanical allodynia in rat models of neuropathic pain. Psychopharmacology (Berl) 2008;195:559-568.

122. Chapman V, Ng J, Dickenson AH. A novel spinal action of mexiletine in spinal somatosensory transmission of nerve injured rats. Pain 1998;77:289-303.

123. Zhang JM, Li H, Munir MA. Decreasing sympathetic sprouting in pathologic sensory ganglia: a new mechanism for treating neuropathic pain using lidocaine. Pain 2004;109:143-149.

124. LaBuda CJ, Little PJ. Pharmacological evaluation of the selective spinal nerve ligation model of neuropathic pain in the rat. $\mathrm{J}$ Neurosci Methods 2005; 144:175-181.

125. Lee YW, Chaplan SR, Yaksh TL. Systemic and supraspinal, but not spinal, opiates suppress allodynia in a rat neuropathic pain model. Neurosci Lett 1995;199:111-114.

126. Field MJ, Bramwell S, Hughes J, Singh L. Detection of static and dynamic components of mechanical allodynia in rat models of neuropathic pain: are they signalled by distinct primary sensory neurones? Pain 1999;83:303-311.

127. Kontinen VK, Paananen S, Kalso E. Systemic morphine in the prevention of allodynia in the rat spinal nerve ligation model of neuropathic pain. Eur J Pain 1998;2:35-42.

128. Suzuki R, Chapman V, Dickenson AH. The effectiveness of spinal and systemic morphine on rat dorsal horn neuronal responses in the spinal nerve ligation model of neuropathic pain. Pain 1999;80:215-228.

129. Zhao C, Tall JM, Meyer RA, Raja SN. Antiallodynic effects of systemic and intrathecal morphine in the spared nerve injury model of neuropathic pain in rats. Anesthesiology 2004;100:905911.

130. Yaksh TL, Pogrel JW, Lee YW, Chaplan SR. Reversal of nerve ligation-induced allodynia by spinal alpha- 2 adrenoceptor agonists. J Pharmacol Exp Ther 1995;272:207-214.

131. Wei H, Pertovaara A. Spinal and pontine alpha2-adrenoceptors have opposite effects on pain-related behavior in the neuropathic rat. Eur J Pharmacol 2006;551:41-49.

132. Jones KL, Finn DP, Governo RJ, et al. Identification of discrete sites of action of chronic treatment with desipramine in a model of neuropathic pain. Neuropharmacology 2009;56:405-413.

133. King T, Rao S, Vanderah T, Chen Q, Vardanyan A, Porreca F. Differential blockade of nerve injury-induced shift in weight bearing and thermal and tactile hypersensitivity by milnacipran. J Pain 2006;7:513-520.

134. Rode F, Thomsen M, Brolos T, Jensen DG, Blackburn-Munro G, Bjerrum OJ. The importance of genetic background on pain behaviours and pharmacological sensitivity in the rat spared serve injury model of peripheral neuropathic pain. Eur J Pharmacol 2007;564:103-111.

135. Pertin M, Allchorne AJ, Beggah AT, Woolf CJ, Decosterd I. Delayed sympathetic dependence in the spared nerve injury (SNI) model of neuropathic pain. Mol Pain 2007;3:21.

136. Zhao C, Chen L, Tao YX, et al. Lumbar sympathectomy attenuates cold allodynia but not mechanical allodynia and hyperalgesia in rats with spared nerve injury. J Pain 2007;8:931-937.

137. Blackburn-Munro G, Ibsen N, Erichsen HK. A comparison of the anti-nociceptive effects of voltage-activated $\mathrm{Na}+$ channel blockers in the formalin test. Eur J Pharmacol 2002;445:231-238.

138. Decosterd I, Allchorne A, Woolf CJ. Differential analgesic sensitivity of two distinct neuropathic pain models. Anesth Analg 2004;99:457-463.

139. Suter MR, Papaloizos M, Berde CB, et al. Development of neuropathic pain in the rat spared nerve injury model is not prevented by a peripheral nerve block. Anesthesiology 2003;99:1402-1408. 
sation of the spared nerve injury model of neuropathic pain. Pain 2002;98:151-161.

141. Erichsen HK, Hao JX, Xu XJ, Blackburn-Munro G. A comparison of the antinociceptive effects of voltage-activated $\mathrm{Na}+$ channel blockers in two rat models of neuropathic pain. Eur J Pharmacol 2003;458:275-282.

142. Berman JS, Birch R, Anand P. Pain following human brachial plexus injury with spinal cord root avulsion and the effect of surgery. Pain 1998;75:199-207.

143. Rodrigues-Filho R, Campos MM, Ferreira J, Santos AR, Bertelli JA, Calixto JB. Pharmacological characterisation of the rat brachial plexus avulsion model of neuropathic pain. Brain Res 2004; 1018:159-170.

144. Gazelius B, Cui JG, Svensson M, Meyerson B, Linderoth B. Photochemically induced ischaemic lesion of the rat sciatic nerve. A novel method providing high incidence of mononeuropathy. Neuroreport 1996;7:2619-2623.

145. Hao JX, Xu IS, Xu XJ, Wiesenfeld-Hallin Z. Effects of intrathecal morphine, clonidine and baclofen on allodynia after partial sciatic nerve injury in the rat. Acta Anaesthesiol Scand 1999;43: 1027-1034.

146. Kupers R, Yu W, Persson JK, Xu XJ, Wiesenfeld-Hallin Z. Photochemically-induced ischemia of the rat sciatic nerve produces a dose-dependent and highly reproducible mechanical, heat and cold allodynia, and signs of spontaneous pain. Pain 1998;76: $45-59$.

147. Hao JX, Blakeman KH, Yu W, Hultenby K, Xu XJ, WiesenfeldHallin Z. Development of a mouse model of neuropathic pain following photochemically induced ischemia in the sciatic nerve. Exp Neurol 2000;163:231-238.

148. Xu XJ, Plesan A, Yu W, Hao JX, Wiesenfeld-Hallin Z. Possible impact of genetic differences on the development of neuropathic pain-like behaviors after unilateral sciatic nerve ischemic injury in rats. Pain 2001;89:135-145.

149. Yu W, Kauppila T, Hultenby K, Persson JK, Xu XJ, WiesenfeldHallin Z. Photochemically-induced ischemic injury of the rat sciatic nerve: a light- and electron microscopic study. J Peripher Nerv Syst 2000;5:209-217

150. Coderre TJ, Xanthos DN, Francis L, Bennett GJ. Chronic postischemia pain (CPIP): a novel animal model of complex regional pain syndrome-type I (CRPS-I; reflex sympathetic dystrophy) produced by prolonged hindpaw ischemia and reperfusion in the rat. Pain 2004;112:94-105.

151. Xanthos DN, Coderre TJ. Sympathetic vasoconstrictor antagonism and vasodilatation relieve mechanical allodynia in rats with chronic postischemia pain. J Pain 2008;9:423-433.

152. Aota Y, Onari K, An HS, Yoshikawa K. Dorsal root ganglia morphologic features in patients with herniation of the nucleus pulposus: assessment using magnetic resonance myelography and clinical correlation. Spine 2001;26:2125-2132.

153. Hu SJ, Xing JL. An experimental model for chronic compression of dorsal root ganglion produced by intervertebral foramen stenosis in the rat. Pain 1998;77:15-23.
154. Zhang JM, Song XJ, LaMotte RH. Enhanced excitability of sensory neurons in rats with cutaneous hyperalgesia produced by chronic compression of the dorsal root ganglion. J Neurophysiol 1999;82:3359-3366.

155. Song XJ, Vizcarra C, Xu DS, Rupert RL, Wong ZN. Hyperalgesia and neural excitability following injuries to central and peripheral branches of axons and somata of dorsal root ganglion neurons. J Neurophysiol 2003;89:2185-2193.

156. Ma C, Greenquist KW, Lamotte RH. Inflammatory mediators enhance the excitability of chronically compressed dorsal root ganglion neurons. J Neurophysiol 2006;95:2098-2107.

157. Song XJ, Hu SJ, Greenquist KW, Zhang JM, LaMotte RH. Mechanical and thermal hyperalgesia and ectopic neuronal discharge after chronic compression of dorsal root ganglia. J Neurophysiol 1999;82:3347-3358.

158. Zhang JM, Li H, Brull SJ. Perfusion of the mechanically compressed lumbar ganglion with lidocaine reduces mechanical hyperalgesia and allodynia in the rat. J Neurophysiol 2000;84:798 805.

159. Jancalek R, Dubovy P. An experimental animal model of spinal root compression syndrome: an analysis of morphological changes of myelinated axons during compression radiculopathy and after decompression. Exp Brain Res 2007;179:111-119.

160. Massie JB, Huang B, Malkmus S, et al. A preclinical post laminectomy rat model mimics the human post laminectomy syndrome. J Neurosci Methods 2004;137:283-289.

161. Aprill C, Bogduk N. High-intensity zone: a diagnostic sign of painful lumbar disc on magnetic resonance imaging. Br J Radiol 1992;65:361-369.

162. Videman T, Nurminen M. The occurrence of anular tears and their relation to lifetime back pain history: a cadaveric study using barium sulfate discography. Spine 2004;29:2668-2676.

163. Olmarker K, Storkson R, Berge OG. Pathogenesis of sciatic pain: a study of spontaneous behavior in rats exposed to experimental disc herniation. Spine 2002;27:1312-1317.

164. Olmarker K. Puncture of a lumbar intervertebral disc induces changes in spontaneous pain behavior: an experimental study in rats. Spine 2008;33:850-855.

165. Shamji MF, Allen KD, So S, et al. Gait abnormalities and inflammatory cytokines in an autologous nucleus pulposus model of radiculopathy. Spine 2009;34:648-654.

166. Hunt D, Hossain-Ibrahim K, Mason MR, et al. ATF3 upregulation in glia during Wallerian degeneration: differential expression in peripheral nerves and CNS white matter. BMC Neurosci 2004; 5:9.

167. Wright DE, Ryals JM, McCarson KE, Christianson JA. Diabetesinduced expression of activating transcription factor 3 in mouse primary sensory neurons. J Peripher Nerv Syst 2004;9:242-254.

168. Jones E, Vinuela-Fernandez I, Eager RA, et al. Neuropathic changes in equine laminitis pain. Pain 2007;132:321-331. 